Cahiers $d u$ MONDE RUSSE

\section{Cahiers du monde russe}

Russie - Empire russe - Union soviétique et États indépendants

$46 / 4 \mid 2005$

L'invention d'une politique humanitaire

\title{
Marlène Laruelle, Sébastien Peyrouse, éds., Islam et politique en ex-URSS
}

Isabelle Ohayon

\section{(2) OpenEdition}

Journals

Édition électronique

URL : https://journals.openedition.org/monderusse/6661

DOI : 10.4000/monderusse.6661

ISSN : $1777-5388$

Éditeur

Éditions de l'EHESS

Édition imprimée

Date de publication : 1 décembre 2005

Pagination : 968-971

ISBN : 2-7132-2057-2

ISSN : $1252-6576$

Référence électronique

Isabelle Ohayon, "Marlène Laruelle, Sébastien Peyrouse, éds., Islam et politique en ex-URSS »,

Cahiers du monde russe [En ligne], 46/4 | 2005, mis en ligne le 30 juin 2009, consulté le 02 septembre 2022. URL : http://journals.openedition.org/monderusse/6661 ; DOI : https://doi.org/10.4000/ monderusse. 6661

Ce document a été généré automatiquement le 2 septembre 2022.

Tous droits réservés 


\title{
Marlène Laruelle, Sébastien Peyrouse, éds., Islam et politique en ex-URSS
}

\author{
Isabelle Ohayon
}

\section{RÉFÉRENCE}

Marlène LARUELLE, Sébastien PEYROUSE, éds., Islam et politique en ex-URSS (Russie d'Europe et Asie centrale). Paris : L'Harmattan-IFEAC, collection Centre-Asie, 2005, $338 \mathrm{p}$.

1 Centré sur les formes de radicalisme et leurs avatars, le débat sur l'islam dans l'ex-URSS est rarement abordé sous l'angle choisi dans cet ouvrage, à savoir celui des rapports quotidiens des institutions et des acteurs avec le politique au sens large et avec les autorités en particulier. En raison de l'éclatement des études dans les différents États issus de l'URSS, la perspective ex-soviétique se trouve fréquemment en marge de la recherche. En excluant le cas caucasien, Marlène Laruelle et Sébastien Peyrouse proposent une synthèse de la question par la publication de cette version enrichie des actes du colloque "Islam et politique en ex-URSS ", qui s'esttenu à Kazan les $1^{\text {er }}$ et 2 avril 2004, à l'initiative de l'Institut français d'études sur l'Asie centrale (IFEAC) et du Centre franco-russe en sciences humaines et sociales de Moscou. Ils satisfont l'ambition affichée de rendre l'échelle d'analyse ex-soviétique pertinente en insérant dans cette perspective les dix-sept contributions et études de cas de ce recueil, et l'explicitent dans une introduction très étoffée qui revient sur les principaux processus caractérisant le binôme islam et politique en Russie d'Europe et en Asie centrale. Parmi les idées fortes qui y sont défendues, on en retiendra au moins trois: l'articulation de l'islam et de la question nationale, les processus de modernisation de la foi et les antécédents historiques de la formation des courants religieux, notamment en Asie centrale. 
2 La quasi-totalité des contributions partage comme arrière-plan l'idée selon laquelle, dans l'espace ex-soviétique, le fait religieux et le fait national sont étroitement articulés, qu'il s'agisse de l'islam ou du christianisme. En ancrant la foi dans les traditions nationales (maintien des cultes anciens islamisés, par exemple) et en revendiquant cette démarche, les institutions religieuses musulmanes confortent en effet ce phénomène, tant en Russie d'Europe qu'en Asie centrale. L'islam ne peut s'y penser comme un phénomène transcendant les appartenances nationales - bien au contraire, puisqu'il leur est soumis - et tend à conforter les élites religieuses locales (S. Abachin, S. Kouchkoumbaev). La prétention à l'universalité y est perçue comme un trait de fondamentalisme qui va à l'encontre de l'ajustement de l'islam populaire à la diversité des groupes sociaux et des réalités régionales, claniques, clientélistes et/ou ethniques (N. Alniazov). D'autre part, dans le cadre des nouveaux États et des républiques fédérées, le recoupement de l'identité nationale et de l'appartenance religieuse semble avoir pour corollaire un effet de communautarisation " ethnoreligieuse ", qui se présente davantage comme une reformulation modernisée du lien entre identité collective et islam qu'un retour en arrière (X. Le Torrivellec).

3 À cette articulation nation/islam sont reliées les mesures de restriction de la liberté de culte, adoptées à des degrés divers par l'ensemble des nouveaux États, qui cherchent à minimiser la diffusion des mouvements sectaires, des courants extérieurs à la région et des groupes extrémistes. L'islam officiel qui, dans cette configuration, trouve comme alliée l'Église orthodoxe confrontée aux mêmes difficultés, s'efforce de maintenir l'identification nationale et d'éliminer les courants qui lui font concurrence ( $\mathrm{S}$. Peyrouse). Cette identification, comme outil de cohésion nationale, implique une grande proximité avec les pouvoirs politiques. Aussi bien en Russie d'Europe qu'en Asie centrale, les Directions spirituelles nationales, héritières des grands organismes soviétiques régionaux du même nom, se trouvent dans une relation de soumission et de contrôle visà-vis des pouvoirs publics. Desservies par un tissu de croyants souvent peu structuré, elles peinent à définir des orientations propres, malgré quelques tentatives infructueuses. Au Tatarstan en particulier, les institutions religieuses n'ont pas réussi à construire de véritable politique confessionnelle (R. Moukhametchin) et restent assujetties au pouvoir fédéral qui manipule le facteur religieux pour asseoir son autorité, mais sans permettre l'émergence d'un projet confessionnel. En Russie, d'une manière générale, les fidèles se reconnaissent rarement dans leurs représentants, qui, de facto, ne sont pas à même de relayer leurs revendications, cette situation marquant une rupture forte avec l'État (F. Daucé). Ce fossé entre croyants et institutions, qui résulte aussi du phénomène d'individualisation de la foi, se traduit notamment par l'indifférence des fidèles aux appels au conservatisme moral. Ainsi, l'idée de "renouveau religieux » dans l'espace soviétique, comme le souligne S. Peyrouse, ne résiste pas longtemps à cette réalité.

4 L'apparent retour de la religion dans l'espace public ne doit pas, en effet, faire illusion. À la profonde crise d'autorité qui touche l'islam et se traduit, par exemple, par la difficulté à promouvoir un enseignement unifié, s'ajoutent les processus classiques de modernisation du rapport à la foi dont le trait majeur est la personnalisation. Forte de l'expérience soviétique de sécularisation, la foi relève désormais d'une conviction et d'un choix individuel libéré des contraintes sociales attachées traditionnellement au culte. Les hiérarchies religieuses se trouvent même obligées de prendre cette évolution en considération en développant des arguments adaptés et elles insistent dorénavant sur les 
notions d'éthique et de développement personnel. Les modes d'adhésion qui reposent sur des logiques individuelles, la multiplication des néo-confréries et le développement de différentes formes d'islam particulières (« islam russe», " euro-islam », " néodjadidisme", "soufisme", "salafisme», etc.) sont également des manifestations de cette « intimisation» du religieux (E. Moroz).

5 On ne pouvait faire l'impasse, dans l'étude de l'islam postsoviétique et de ses rapports avec le pouvoir, sur l'analyse du passé soviétique. À cet égard, cet ouvrage apporte des éléments très intéressants pour l'histoire récente de la structuration des institutions et des courants religieux en Asie centrale et éclaire remarquablement certains événements contemporains. L'accès aux sources, et plus encore la nouvelle liberté d'expression, ont contribué à renouveler les analyses de l'islam centrasiatique et à nuancer certaines hypothèses développées notamment en Occident par l'école Bennigsen. Le soufisme populaire apparaît ainsi, sous la plume de S. Abachin, comme un ensemble, non pas de confréries, mais de traditions et de courants très peu hiérarchisés et indépendants les uns des autres, dont la structure n'est pas socialement unifiée. L'appartenance à un courant, à l'époque soviétique, recoupait selon lui des groupes de filiation plus qu'elle ne faisait appel à une intellectualisation du soufisme et à une pratique mystique. Elle pouvait néanmoins constituer le support de logiques clientélistes et demeure toujours aujourd'hui susceptible de se structurer politiquement. Sur ce point, A. Kariev montre, dans sa contribution sur la vallée du Ferghana dans les années 1970 et 1980, comment, par un réseau d'écoles souterrain, se perpétuaient la connaissance des rites principaux de l'islam et une pratique quotidienne. Dans ce contexte, au plus fort du durcissement athéiste du régime soviétique dans cette partie de l'Ouzbékistan, s'est développée une mouvance radicale portée par un groupe social composé de négociants et de producteurs clandestins, partisans d'un changement de régime politique et d'une «purification » des pratiques religieuses. Il est tentant de trouver là un élément de continuité propre à éclairer les événements d'Andijan du mois de mai 2005, où un groupe d'entrepreneurs influents en collusion avec des fondations islamiques a été l'une des cibles du gouvernement ouzbékistanais.

6 Enfin, non sans lien avec la «scission » présentée par A. Kariev parmi les croyants du Ferghana, A. Muminov rend compte de certains mécanismes de transmission des idées fondamentalistes au sein de la Direction spirituelle des musulmans d'Asie centrale et du Kazakhstan, et de l'introduction, à travers le débat théologique, d'éléments rigoristes issus de la tradition juridiquechaféite dans l'islam de cette région traditionnellement hanéfite. Remettant en cause l'idée de la soumission de la Direction spirituelle au pouvoir soviétique, d'ailleurs parfaitement au fait des tendances conservatrices de cette institution et passablement responsable de l'extinction du courant réformateur djadide, cette contribution révèle combien le fondamentalisme, voire le salafisme actuel, plongent leurs racines dans l'histoire soviétique.

7 On dira, pour conclure, que malgré l'inévitable hétérogénéité de l'exercice consistant à réunir les actes d'un colloque, l'ouvrage parvient à dessiner une synthèse cohérente des grandes évolutions de la question musulmane depuis quinze ans dans l'espace exsoviétique. 